\title{
Penatalaksanaan Anestesi Pasien Transposition of the Great Arteries pada Operasi Mouth Preparation
}

\author{
Ade Aria Nugraha, Suwarman, Ardi Zulfariansyah \\ Departemen Anestesiologi dan Terapi Intensif \\ Fakultas Kedokteran Universitas Padjadjaran/Rumah Sakit Dr. Hasan Sadikin Bandung
}

\begin{abstract}
Abstrak
Transposition of the great arteries (TGA) disebabkan kegagalan pemisahan trunkus arteriosus, sehingga aorta keluar dari bagian anterior ventrikel kanan dan arteri pulmonal keluar dari ventrikel kiri. TGA termasuk kelainan jantung bawaan tipe sianotik. Laporan kasus ini bertujuan memaparkan konsiderasi penatalaksanaan anestesia pada pasien TGA. Seorang anak perempuan berusia 4 tahun datang untuk perawatan dan pencabutan gigi sebagai persiapan untuk operasi koreksi TGA di Rumah Sakit Dr. Hasan Sadikin Bandung pada Januari 2014. Anamnesis didapatkan riwayat kebiruan sejak bayi dan pada pemeriksaan fisis didapatkan anak yang tampak sianosis, $\mathrm{SpO}_{2} 70-80 \%$, murmur sistol, dan jari tabuh. Pada pemeriksaan ekokardiografi didapatkan kelainan TGA. Manajemen anestesi pada pasien ini dilakukan dengan menggunakan ketamin dan vekuronium untuk induksi serta pemeliharaan dengan $\mathrm{O}_{2}$ dan air, serta sevofluran. Manajemen anestesi dilakukan dengan target mencegah penurunan miring systemic vascular resistance (SVR) dibandingkan dengan pulmonary vascular resistance (PVR). Simpulan, prinsip pengelolaan perioperatif pembedahan nonkardiak pada pasien TGA adalah menjaga agar tidak terjadi penurunan SVR dan peningkatan PVR.
\end{abstract}

Kata kunci: Kelainan jantung kongenital sianotik, pulmonary vascular resistance (PVR), systemic vascular resistance (SVR), transposition of the great arteries (TGA)

\section{Management of Anesthesia in Transposition of the Great Arteries Patient Undergoing Mouth Preparation Surgery}

\begin{abstract}
Transposition of the great arteries (TGA) results from failure of the truncus arteriosus to spiral leading to, aorta arises from the anterior portion of the right ventricle and pulmonary artery arises from the left ventricle. TGA is a type of cyanotic congenital heart disease. A 4-year-old girl came for treatment and tooth extraction as the preparation for TGA surgical correction of at Dr. Hasan Sadikin General Hospital Bandung in January 2014. Patient had a history cyanosis when she was a baby and, on physical examination, was found cyanotic child looking cyanosis, with $\mathrm{SpO}_{2}$ of $70-80 \%$, syistolic murmur, and clubbing finger. Abnormalities on echocardiography showed TGA condition. Anesthetic management for this patients was performed using ketamine and vecuronium for induction and $\mathrm{O}_{2}, \mathrm{~N}_{2} \mathrm{O}$, and sevoflurane for maintenance. This management was targeted to prevent cyanotic attacks by increasing systemic vascular resistance (SVR) compared to pulmonary vascular resistance. In conclusion, perioperative management principle for non-cardiac surgery in transposition of the great arteries (TGA) patient is to keep SVR from declining and to increase PVR.
\end{abstract}

Key words: Cyanotic congenital heart defects, pulmonary vascular resistance (PVR), systemic vascular resistance (SVR), transposition of the great arteries (TGA)

Korespondensi: Ade Aria Nugraha, dr, Departemen Anestesiologi dan Terapi Intensif Fakultas Kedokteran Universitas Padjadjaran/Rumah Sakit Dr. Hasan Sadikin, Jl. Pasteur No. 38, Bandung, Telp. 022-2038285, Mobile 081271536100, Email adearianugraha@gmail.com 


\section{Pendahuluan}

Transposition of great arteries atau TGA adalah penyakit jantung bawaan (PJB) jenis sianotik yang bermanifestasi pada saat bayi baru lahir. Kelainan ditemukan sekitar 5-7\% dari seluruh penyakit jantung bawaan, terutama pada lakilaki. Insidens TGA diperkirakan 1:3.500-5.000 kelahiran hidup. Etiologi TGA adalah gangguan embriologi pada waktu pembentukan trunkus arterial. Faktor genetik diduga berperan pada terjadinya TGA. Tanpa dilakukan terapi koreksi pembedahan, $30 \%$ kasus akan meninggal pada minggu pertama kehidupan dan $90 \%$ pada usia satu tahun. Survival rate 5 tahun pascakoreksi bedah dapat lebih dari $80 \%$. Kelainan penyerta tersering ditemukan adalah ventricular septal defect (VSD), atrial septal defect (ASD), patent ductus arterious (PDA), dan juga left ventricular outflow tract obstruction. ${ }^{1}$

Pada kasus TGA terjadi perubahan tempat keluar dari pembuluh darah besar, aorta keluar melalui ventrikel kanan serta terletak anterior terhadap arteri pulmonalis, sedangkan arteri pulmonalis keluar melalui ventrikel kiri serta terletak posterior terhadap aorta. Akibatnya, aorta akan menerima darah vena sistemik yang berasal dari vena kava, atrium kanan, ventrikel kanan, kemudian aliran darah ini diteruskan ke sirkulasi sistemik, sedangkan darah dari vena pulmonalis dialirkan ke atrium kiri, ventrikel kiri, dan diteruskan ke arteri pulmonalis serta paru. Pada keadaan tersebut sirkulasi sistemik maupun paru menjadi sirkulasi yang terpisah dan kehidupan hanya dapat berlangsung bila terdapat komunikasi antara 2 sirkulasi ini. ${ }^{2}$

Jadi terdapat dua sirkulasi paralel. Keadaan tersebut tidak menjamin pasien hidup kecuali ada pencampuran darah pada atrium (melalui defek septum atrium atau foramen ovale) atau antara kedua ventrikel (melalui defek septum ventrikel), ataupun pada arteri besar (melalui duktus arteriosus). ${ }^{2,3}$

Transposition of great arteries merupakan penyakit jantung bawaan tipe sianotik kedua tersering setelah kasus Tetralogy Fallot, kirakira 5\% dari seluruh penyakit jantung bawaan. Kelainan ini lebih sering ditemukan pada anak laki-laki. Sepertiga kasus mempunyai riwayat ibu yang menderita diabetes melitus. Bayi TGA jarang lahir prematur, biasanya ia lahir dengan berat badan normal atau besar. ${ }^{1}$

Manifestasi klinis pasien TGA ditentukan oleh derajat pencampuran darah yang terjadi, pasien akan tampak mengalami sianosis ringan sampai berat. Pada auskultasi terdengar bunyi jantung II tunggal yang disebabkan oleh bunyi katup pulmonal yang bersembunyi di belakang katup aorta. Bising dapat tidak ada sama sekali sampai bising pansistolik atau bising kontinu melalui duktus arteriosus. ${ }^{2,3}$

Patent ductus arteriosus (PDA) merupakan duktus arteriosus yang tetap terbuka. Duktus arteriosus berasal dari arkus aorta pada janin dan menghubungkan arteri pulmonalis dengan aorta desendens. Pada bayi normal saluran ini menutup secara fungsional 10-15 jam setelah lahir dan secara anatomis menjadi ligamentum arteriosum pada usia 2-3 minggu, bila tidak menutup disebut dengan PDA. Pada saat lahir, ketika bayi mulai bernapas, duktus arteriosus akan menutup karena darah harus mengalir ke paru-paru agar mengandung banyak oksigen. Setelah persalinan terjadi perubahan sirkulasi dan juga fisiologis yang dimulai segera setelah eliminasi plasenta dari neonatus. Perubahan tekanan, sirkulasi, dan juga peningkatan $\mathrm{pO}_{2}$ akan menyebabkan terjadi penutupan spontan pada duktus arteriosus dalam waktu 2 minggu, PDA akan mengakibatkan pirai (shunt) kiri ke kanan yang dapat mengakibatkan hipertensi pulmonal dan sianosis. Besarnya pirai (shunt) ditentukan oleh diameter, panjang PDA, serta tahanan vaskular paru (PVR). ${ }^{2,3}$

Pada 95\% bayi yang baru lahir, penutupan duktus terjadi dalam waktu 48-72 jam. Pada beberapa kasus, duktus ini tidak menutup atau hanya menutup sebagian. Hal ini terjadi karena tidak terdapatnya sensor oksigen yang normal pada otot duktus atau disebabkan kelemahan otot duktus tersebut. Faktor risiko terjadinya PDA adalah prematuritas serta sindrom gawat pernapasan. $^{3}$

Manifestasi klinis PDA terjadi bila duktus tetap terbuka, darah yang seharusnya mengalir ke seluruh tubuh kembali lagi ke paru-paru, hal ini mengakibatkan darah memenuhi pembuluh darah paru-paru. Jumlah darah tambahan yang 
sampai ke paru-paru bergantung pada ukuran PDA. Jika PDA berukuran sangat kecil, maka darah yang melewati PDA hanya sedikit. Pada keadaan ini, anak tidak memiliki gejala sama sekali dan tampak baik-baik saja. ${ }^{2,3}$

Ventricular septal defect (VSD) merupakan kelainan kongenital septum interventrikular yang terbuka sehingga terjadi hubungan darah antara ventrikel kiri dan kanan. Kelainan VSD disebabkan malformasi embriogenik septum interventrikularis. Aliran darah yang melalui defek itu lebih sering bertipe left to right shunt dan bergantung ukuran defek, serta resistensi vaskular pulmoner. Kelainan fungsi jantung penderita juga akan bergantung pada ukuran defek tersebut dan juga resistensi pembuluh darah pulmoner. ${ }^{2,3}$ Semakin besar pirau maka semakin berkurang darah yang melalui katup aorta dan makin banyak volume darah jaringan intratorakal. Berkurangnya darah pada sistem sirkulasi mengakibatkan pertumbuhan badan terlambat dan juga infeksi saluran napas yang berulang. Pada VSD kecil anak dapat tumbuh sempurna tanpa disertai keluhan, sedangkan pada VSD besar dapat mengakibatkan terjadi gagal jantung dini. ${ }^{4-6}$

Laporan kasus ini bertujuan memaparkan konsiderasi penatalaksanaan anestesia pada pasien TGA.

\section{Laporan Kasus}

Seorang anak perempuan usia 4 tahun dengan diagnosis multiple caries rahang atas dan juga rahang bawah yang disertai TGA, VSD, dan PDA dikonsulkan ke Departemen Anestesiologi dan Terapi Intesif Rumah Sakit Dr. Hasan Sadikin Bandung pada 3 Januari 2014 untuk dilakukan mouth preparation dalam anestesia umum. Dari anamnesis didapatkan keterangan bahwa pasien ini mempunyai kelainan jantung bawaan sejak usia 7 bulan. Pasien mengalami kebiruan pada bibir dan juga ujung jari ketika menangis. Kebiruan pada kulit ini kemudian menetap dan bertambah saat pasien menangis atau kurang beristirahat. Pasien tidak pernah dirawat atau menjalani terapi karena kelainan jantung. Pasien dilahirkan spontan di rumah sakit, cukup bulan, berat badan lahir $3 \mathrm{~kg}$, tetapi tidak langsung menangis. Riwayat kehamilan ibu didapatkan bahwa ibu pasien mengalami Ventricular Septal Defect (VSD)

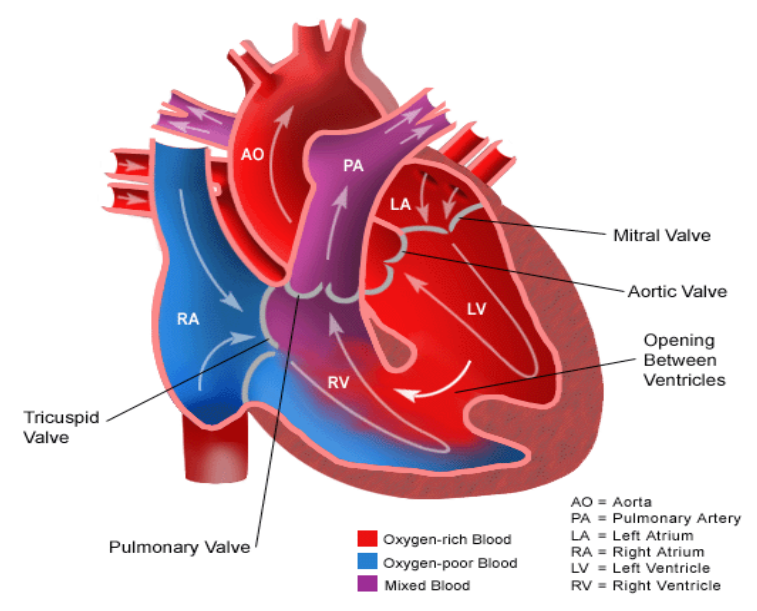

Gambar 1 Jantung dengan VSD Sumber: Congenital Heart Defects ${ }^{4}$
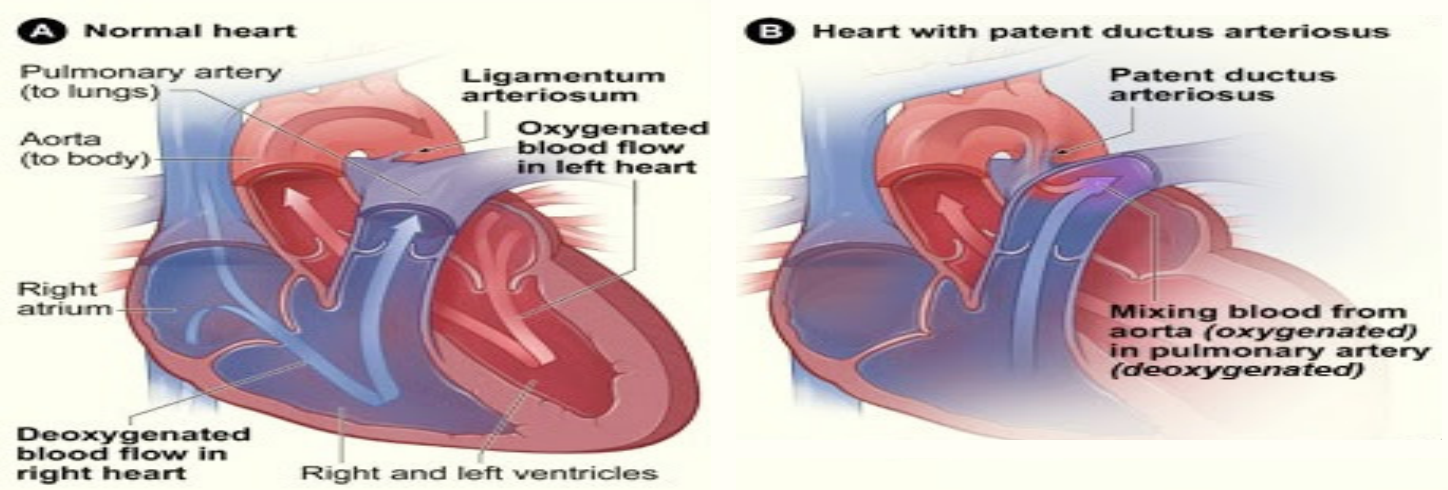

Gambar 2 Jantung Normal dan Jantung dengan PDA

Sumber: Congenital Heart Defects ${ }^{4}$ 

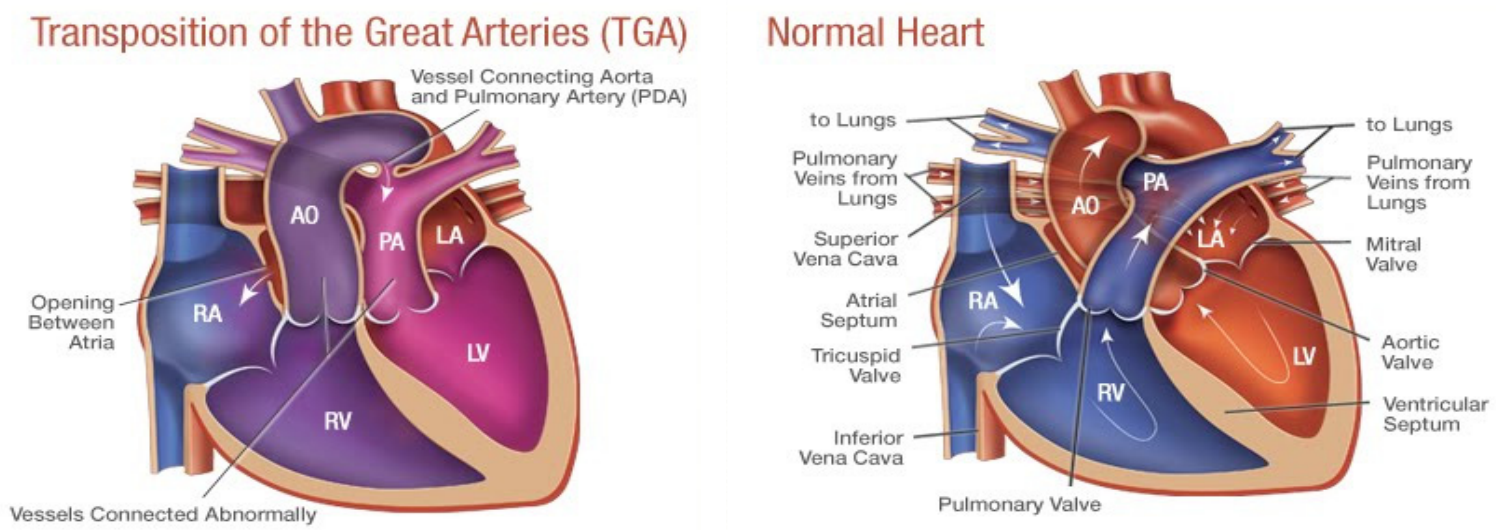

$$
\begin{array}{r}
\text { AO: Aorta } \quad \text { PA: Pulmonary Artery } \\
\quad \text { Oxygen-rich Blood }
\end{array}
$$

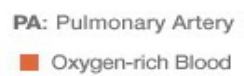

LA: Left Atrium Oxygen-poor Blood

RA: Right Atrium LV: Left Ventricle RV: Right Ventricle

Gambar 3 TGA dan Normal Jantung

Sumber: Congenital Heart Defects ${ }^{4}$

tekanan darah tinggi sejak pertengahan masa kehamilan. Tidak ada riwayat kelainan jantung bawaan pada keluarga pasien. Saat ini pasien tidak mendapatkan terapi apapun.

Pada pemeriksaan fisis pasien didapatkan berat badan $11 \mathrm{~kg}$, kesadaran kompos mentis, tanda-tanda vital, yaitu tekanan darah 104/59 $\mathrm{mmHg}$, laju nadi $120 \mathrm{x} /$ menit, laju napas 38 $\mathrm{x} /$ menit, $\mathrm{SpO}_{2}$ 70-80\% dengan udara bebas, suhu $36,1^{\circ} \mathrm{C}$. Pemeriksaan kepala didapatkan konjungtiva tidak anemis, sklera tidak ikterik, mukosa bibir tampak sianosis. Pemeriksaan leher dalam batas normal. Hasil pemeriksaan toraks didapatkan bentuk serta gerak simetris, terlihat retraksi interkosta serta suprasternal, pemeriksaan auskultasi paru didapatkan suara napas vesikular paru antara lapang paru kiri dan kanan sama, tidak ditemukan wheezing serta ronki. Pemeriksaan jantung didapatkan bunyi murmur sistol di celah interkosta II kiri. Pada hasil pemeriksaan abdomen didapatkan bentuk datar dengan konsistensi lembut, serta bising usus normal. Pemeriksaan ekstremitas akral teraba hangat, ujung jari tampak sianosis serta terdapat clubbing finger.

Pemeriksaan darah didapatkan hasil kadar hemoglobin (Hb) 16,4 g/dL, hematokrit (Ht)
62\%, leukosit 6.100/uL, trombosit 242.000/ uL, kadar SGOT 35U/L, SGPT 8U/L, ureum 14 $\mathrm{mg} / \mathrm{dL}$, kreatinin $0,22 \mathrm{mg} / \mathrm{dL}$, natrium 137 $\mathrm{mmoL} / \mathrm{L}$, kalium 3,6 $\mathrm{mmoL} / \mathrm{L}$, gula darah sewaktu $70 \mathrm{mg} / \mathrm{dL}$, PT 14 detik, INR 1, aPTT 34 detik. Gambaran rongent toraks didapatkan kardiomegali dengan bentuk apeks membulat serta tidak terdapat gambaran TB paru aktif. Hasil pemeriksaan ekokardiografi didapatkan gambaran aorta keluar dari ventrikel kanan, arteri pulmonalis keluar melalui ventrikel kiri, terdapat hubungan antara arteri-arteri besar, VSD perimembran besar, dan PDA $4 \mathrm{~mm}$.

Pada saat preoperatif pasien dipuasakan terhadap susu formula selama 6 jam, air susu ibu selama 4 jam, dan dilakukan pemasangan akses intravena di ruang perawatan. Pada saat berada di dalam kamar operasi didapatkan tanda vital tekanan darah 115/62 mmHg, laju nadi $141 \mathrm{x} /$ menit, laju napas $28 \mathrm{x} /$ menit, serta $\mathrm{SpO}_{2} 84 \%$. Induksi dilakukan dengan memakai ketamin $20 \mathrm{mg}$, vekuronium 1,5 mg, dan juga fentanil 20 mcg melalui intravena, kemudian dilakukan intubasi memakai pipa endotrakeal non-kingking no. 4,0 dengan kedalaman 14 $\mathrm{cm}$ dan dihubungkan dengan mesin anestesia. Pada saat operasi berlangsung pemeliharaan 
anestesia menggunakan $\mathrm{O}_{2}$, air, dan sevofluran. Keadaan hemodinamik selama proses operasi berlangsung dengan tekanan darah sistol 89$125 \mathrm{mmHg}$, diastol 58-75 mmHg, laju nadi 126-145 x/menit, laju napas $25-30 \mathrm{x} /$ menit dengan kontrol ventilasi positif secara manual, $\mathrm{SpO}_{2}$ 80-94\%. Jumlah cairan yang diberikan $\pm 500 \mathrm{~mL}$ kristaloid dengan jumlah perdarahan $\pm 30 \mathrm{~mL}$.

Pembedahan berlangsung selama 1 jam 45 menit. Saat pascaoperatif diberikan analgetik ketoprofen supositoria dosis $50 \mathrm{mg}$, kemudian pasien dipindahkan menuju ruang pemulihan. Hasil pemeriksaan tanda vital anak diperoleh tekanan darah 107/64 mmHg, laju nadi 142 $\mathrm{x} /$ menit, laju napas $32 \mathrm{x} /$ menit, dan nilai $\mathrm{SpO}_{2}$ $90 \%$. Pasien diobservasi di ruang pemulihan selama 2 jam dalam kondisi stabil, kemudian dipindahkan ke ruang perawatan.

\section{Pembahasan}

Pada kasus di atas seorang anak datang untuk melakukan perawatan gigi sebagai persiapan untuk operasi koreksi transposition of the great arteries (TGA). Keadaan ini dilakukan karena infeksi gigi dapat menjadi fokal infeksi terjadi komplikasi endokarditis setelah dilakukannya operasi jantung. Pemeriksaan pada penderita ini didapatkan tanda serta gejala yang sesuai dengan gambaran kelainan jantung bawaan, yaitu transposition of the great arteries (TGA). Pasien TGA akan terlihat sianotik sejak awal kelahiran dan akan semakin memberat sejalan peningkatan aktivitas fisik anak. Pada pasien ini sianotik mulai tampak saat berusia 7 bulan dan semakin jelas ketika anak menangis atau saat terjadi peningkatan aktivitas fisik.

Serangan sianosis akibat TGA terjadi baik secara spontan ataupun ketika anak menangis, defekasi, agitasi, injuri, atau pada saat demam sehingga akan meningkatkan tonus simpatis dengan kontraktilitas jantung yang meningkat. Diagnosis TGA pasien ini adalah berdasarkan anamnesis, pemeriksaan fisis, serta didukung pemeriksaan penunjang antara lain rontgen toraksyang menunjukkan kardiomegalidengan apeks yang membulat menyerupai gambaran egg shape. Pada gambaran jantung tersebut menunjukkan kardiomegali terutama bagian ventrikel kanan. Akibat aorta yang bermuara di ventrikel kanan maka beban dari ventrikel kanan akan meningkat karena berperan pada peredaran darah sistemik. Diagnosis pasti TGA didapatkan dari pemeriksaan ekokardiografi yang pada pasien ini didapatkan bahwa aorta keluar dari ventrikel kanan, sedangkan arteri pulmonalis keluar dari ventrikel kiri.

Pada pemeriksaan darah didapatkan kadar $\mathrm{Hb}$ yang tinggi sebagai kompensasi terhadap hipoksia kronik, sedangkan hasil pemeriksaan laboratorium lain masih dalam batas normal. Hipoksia terjadi sebagai akibat percampuran antara darah arteri dan vena karena terdapat defek VSD pada pasien ini. Untuk memenuhi kebutuhan oksigenasi jaringan, maka tubuh melakukan kompensasi dengan meningkatkan jumlah sel-sel darah merah yang pada pasien ini ditemukan kadar hemoglobin meningkat menjadi $16,4 \mathrm{~g} / \mathrm{dL}$ dengan nilai hematokrit $62 \%$, sedangkan nilai yang normal untuk anak usia 2-12 tahun adalah hemoglobin 12-15 g/ $\mathrm{dL}$ dengan nilai hematokrit 37-40\%. Kadar hematokrit yang tinggi ini akan meningkatkan risiko trombosis perioperatif.

Kateter intravena dipasang pada saatpasien berada di ruangan dengan menggunakan cairan Ringer laktat dengan kecepatan pemberian 42 $\mathrm{mL} / \mathrm{jam}$ (14 tetes/menit macro drips) selama pasien puasa preoperatif. Pasien dipuasakan selama enam jam sebelum operasi. Pemberian cairan selama puasa tersebut bertujuan untuk menghindari hipovolumia dan dehidrasi yang akan berakibat peningkatan viskositas darah sehingga risiko trombosis perioperatif dapat diminimalisir. Pada pasien ini durante maupun pascaoperatif tidak ditemukan tanda-tanda trombosis vena serebri.

Hasil anamnesis tidak didapat keterangan pasien mengonsumsi obat golongan antagonis B-adrenergik dan tidak ada riwayat dirawat di rumah sakit, sehingga pasien ini kemungkinan belum pernah mendapatkan suatu komplikasi yang berat akibat TGA. Riwayat pengobatan pada pasien dengan penyakit jantung bawaan yang harus ditanyakanyaituriwayatpemakaian aspirin, warfarin, antidepresan, diuretik, ace inhibitor, serta antiaritmia. Penggunaan obat- 
obatan tersebut harus dipertimbangkan dalam memberikan anestesia karena efek samping akibat pemakaian obat tersebut, namun pada pasien ini tidak ditemukan riwayat pemakaian obat-obatan tersebut.

Prinsip manajemen anestesi pada pasien TGA adalah pertimbangan terhadap sirkulasi yang terpisah antara sirkulasi pulmoner dan sistemik, sehingga pemberian obat anestesia melalui intravena akan terdistribusi terhadap organ seperti jantung maupun otak dengan dilusi yang minimal, sehingga dosis dan juga kecepatan pemberian obat anestesia intravena harus dikurangi. Onset obat-obatan anestesia inhalasi akan menjadi lebih lama karena hanya sejumlah kecil anestesi inhalasi yang mencapai sirkulasi sistemik.

Jenis induksi yang digunakan dapat berupa inhalasi maupun intravena bergantung pada dosis dan juga kecepatan. Pada penggunaan obat anestesi intravena perlu dipertimbangkan keseimbangan dari systemic vascular resistance (SVR) terhadap pulmonary vascular resistance (PVR). Pemilihan obat induksi anestesia pada pasien ini mempergunakan ketamin intravena dosis $2 \mathrm{mg} / \mathrm{kgBB}$. Pemilihan ketamin adalah berdasarkan pengaruh ketamin yang dapat meningkatkan denyut jantung, tekanan darah, cardiac output, serta meningkatkan SVR yang dominan bila dibandingkan dengan tahanan pembuluh darah paru (PVR).

Pemakaian ketamin juga memberikan efek analgetik tanpa menimbulkan depresi napas. Selain ketamin, dapat dipakai etomidat sebagai alternatif, karena memiliki efek yang minimal terhadap kardiovaskular dan juga penurunan tahanan vaskular sistemik, serta tidak bersifat melepaskan histamin.

Konsiderasi anestesia pada pasien dengan TGA adalah mencegah terjadinya penurunan cardiac output (CO) dan SVR, dan menjaga agar PVR lebih rendah dibandingkan dengan SVR. Meningkatkan aliran darah pulmonalis sebagai dampak penurunan PVR akan mengakibatkan peningkatan darah yang tercampur sehingga akan didapatkan saturasi yang lebih tinggi.

Pulmonary vascular resistance (PVR) dapat dikurangi dengan pemberian inhalasi nitrouse oxide (NO), intervensi ventilasi, peningkatan konsentrasi $\mathrm{O}_{2}$, mengurangi karbondioksida, membuat $\mathrm{pH}$ menjadi lebih alkalosis. Pada saat bersamaan harus mencegah terjadi hipoksia, hiperkarbia, asidosis, hipotermia, tidal volume yang terlalu tinggi atau terlalu rendah, positive end expiratory pressure (PEEP) yang tinggi, dan hipoglikemia pada neonatus.

Pada saat awal induksi didapatkan tekanan darah sistol berkisar 100-110 mmHg dengan diastol 60-70 mmHg. Selama anestesia terjadi penurunan tekanan darah berkisar $80 \mathrm{mmHg}$ untuk sistol serta $60 \mathrm{mmHg}$ untuk diastol, hal ini disebabkan antara lain akibat pengaruh sevofluran yang mempunyai sifat depresi pada kontraktilitas otot jantung serta menurunkan tahanan vaskular sistemik serta tekanan darah arteri walaupun lebih kecil bila dibandingkan dengan volatil lain seperti isofluran ataupun desfluran. Kondisi ini menjadi pertimbangan pemakaian sevofluran pada operasi ini.

Penurunan tekanan darah yang berlebihan akibat penurunan tahanan vaskular sistemik menyebabkan right to left shunt yang semakin besarsehinggaberakibatburukditandaidengan terjadi desaturasi pada pasien. Pemeliharaan anestesia dilakukan dengan menggunakan $\mathrm{O}_{2}$, air, dan sevofluran. Pada operasi ini $\mathrm{N}_{2} \mathrm{O}$ tidak dipakai dalam pemeliharaan dengan harapan dapat memberikan fraksi oksigen yang lebih tinggi. Selama operasi tidak terjadi desaturasi dengan saturasi tetap dipertahankan sekitar 85-90\% sesuai saturasi pasien sehari-hari.

Pelemas otot yang digunakan saat induksi ialah vekuronium dengan dosis $0,12 \mathrm{mg} / \mathrm{kgBB}$. Pertimbangan pemakaian vekuronium sebagai pelemas otot dikarenakan vekuronium tidak menyebabkan pelepasan histamin yang dapat menimbulkan vasodilatasi sistemik sehingga mengakibatkan penurunan SVR.

\section{Simpulan}

Prinsip manajemen anestesia pada pasien TGA adalah mencegah terjadi penurunan cardiac output dan SVR sementara itu kita tetap harus menjaga PVR agar lebih rendah dibandingkan dengan SVR. Aliran darah pulmonalis yang meningkat sebagai akibat dari penurunan PVR 
akan mengakibatkan peningkatan darah yang tercampur sehingga memungkinkan mendapat saturasi yang lebih tinggi. Pada pasien ini juga didapatkan PDA yang manajemen anestesinya akan bergantung pada prematuritas, tingkat obstruksi paru, PVR serta teknik operasi yang akan dilakukan. Untuk membatasi left to right shunt dapat dilakukan dengan menjaga $\mathrm{FiO}_{2}$ rendah serta $\mathrm{PaCO}_{2} 40$ hingga $50 \mathrm{mmHg}$. Pada pasien dengan VSD perlu mempertimbangkan PVR yang meningkat dan harus dapat segera menangani PVR yang tinggi dan gagal ventrikel kanan dengan pemberian $\mathrm{NO}_{2}$, dobutamin.

\section{Daftar Pustaka}

1. Morgan GE, Mikhail MS, Murray MJ. Pediatric anesthesia. Dalam: Butterworth JF, Mackey DC, John Wasnick J, penyunting. Clinical anesthesiology. Edisi ke-5. Stanford: Appleton \& Lange; 2013. hlm. 877.
2. Barash P, Cullen BF, Stoelting RK, Calahan M, Stock MC. Pediatric anesthesia. Dalam: Barash P, Cullen BF, Stoelting RK, Cahalan MK, Stock MC, Ortega R, penyunting. Clinical anesthesia. Edisi ke-7. Lippincott Williams \& Wilkins; 2013. hlm. 1206.

3. Bissonnette B, Dalens BJ. Maintenance techniques: pediatric anesthesia principles and practice. New York: McGraw-Hill. 2002.

4. Congenital Heart Defects (diunduh 2 Maret 2014). Tersedia dari: https:// www.heart.org/HEARTORG/Conditions/ CongenitalHeartDefects.

5. Menghraj SJ. Anaesthetic consideration in children with congenital heart disease undergoing non-cardiac surgery. Indian J Anaesth. 2012;56(5):491-5.

6. Anaesthetic considerations for congenital heart disease patient (diunduh 2 Maret 2014) Tersedia dari: https: //www. intechopen.com/download/pdf/ 30197. 